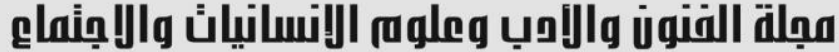

Journal of Arts, Literature, Humanities and Social Sciences www.jalhss.com

\title{
حوكمة ادارة الارباح في شركة التأمين العراقية العامة ودوره في تنمية الاقتصاد الوطني الونين
}

\author{
م.م. غروب كامل محمد \\ قسم الاراســـــــات و التخطيط ـ رئاسة جامعة بغداد ــ العراق \\ الايميل: mohammeghuroob25@gmail.com
}

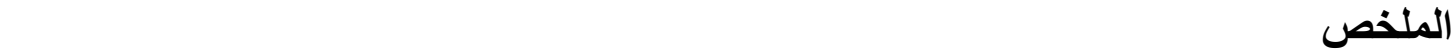

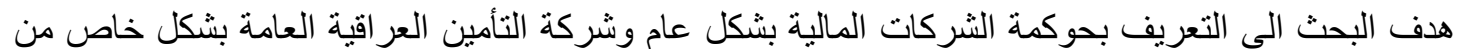

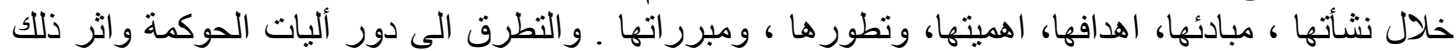

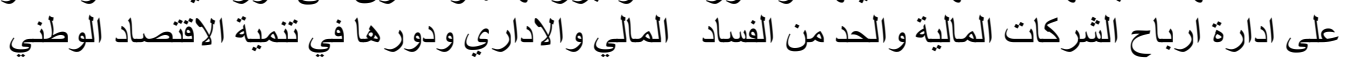

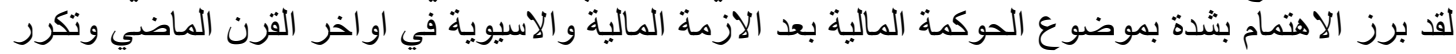

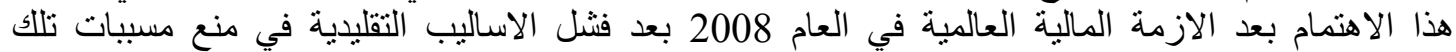

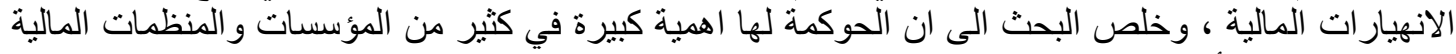

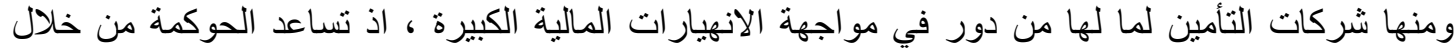

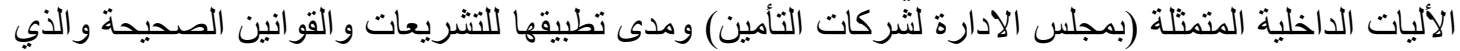

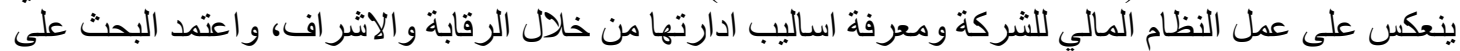

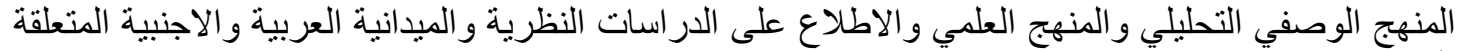

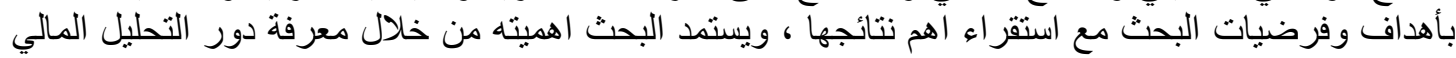

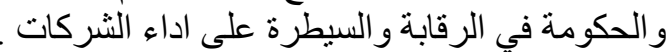

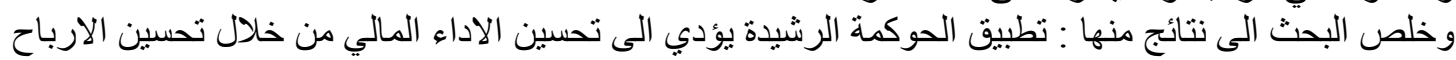

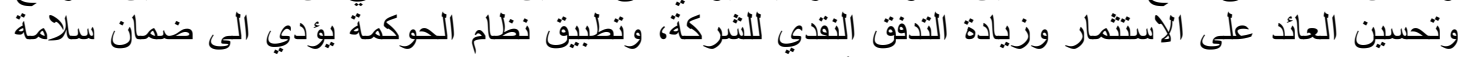

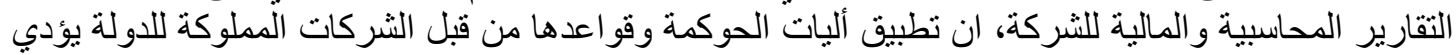

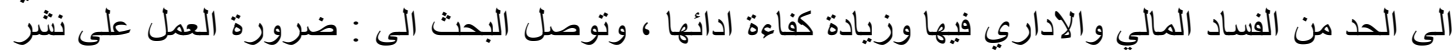

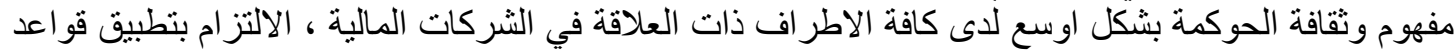

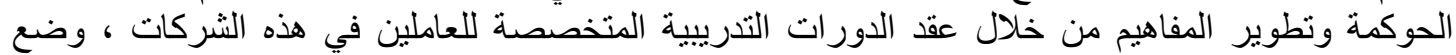

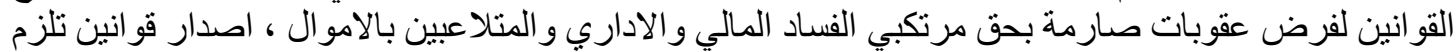

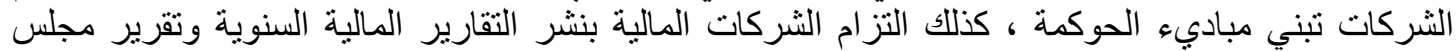
الادارة وتقرير مراقب الحسابات وان تتضمن هذه التقارير المؤشرات المالية وغير المالية التي تعكس اداء

الكلمات المفتاحية: آليات الحوكمة، اداء الثركات المالية، الافصاح، جودة التقارير المالية. 


\begin{tabular}{|c|c|}
\hline \pm & 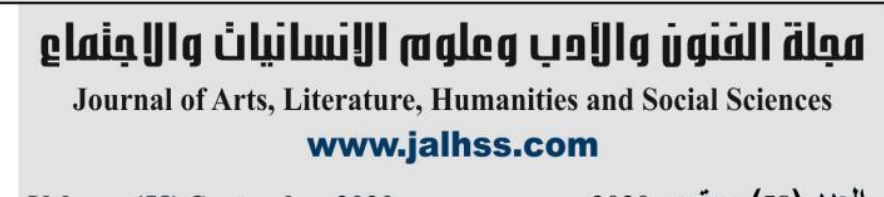 \\
\hline & Volume (58) September 2020 \\
\hline
\end{tabular}

Ghuroob Kamal Mohammed

Studies and Planning Department - University of Baghdad Presidency -Iraq

Email: mohammeghuroob25@gmail.com

\begin{abstract}
The aim of the research is to introduce the governance of financial companies in general and the Iraqi general insurance company in particular through its origins, principles, goals, importance, development, and justifications. And to address the role of governance mechanisms and the impact of this on managing the profits of financial companies and reducing financial and administrative corruption and its role in developing the national economy.

There has been a strong interest in the issue of financial governance after the financial and Asian crisis in the last century, and this interest was repeated after the global financial crisis in 2008 after the failure of traditional methods to prevent the causes of these financial collapses, and the research concluded that governance has a great importance in many financial institutions and organizations including insurance companies, because they have a role in facing large financial collapses, as governance helps through the internal mechanisms represented (the board of directors of insurance companies) and the extent of their application of the correct legislation and laws, which is reflected in the work of the company's financial system and knowledge of its management methods through control and supervision, and the research relied on the descriptive, analytical method and the scientific method and access to Arab and foreign theoretical and field studies related to the goals and hypotheses of the research with extrapolation of the most important results, and the research derives its importance through knowing the role of financial analysis and government in monitoring and controlling the performance of companies.
\end{abstract}

Keywords: governance mechanisms, financial company, performance, disclosure, quality of financial reports. 


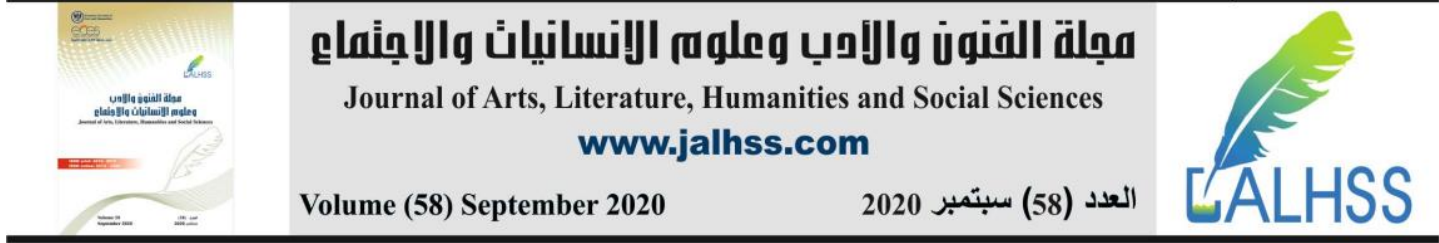

المقدمة

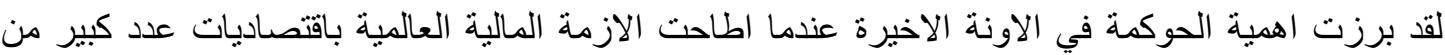

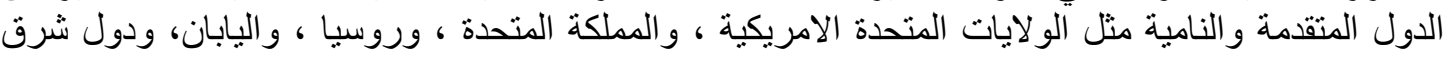

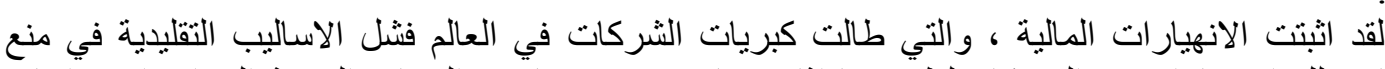

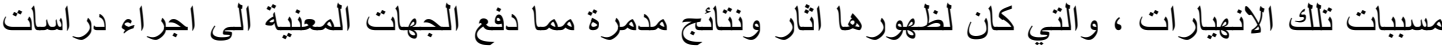

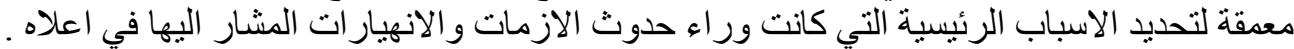

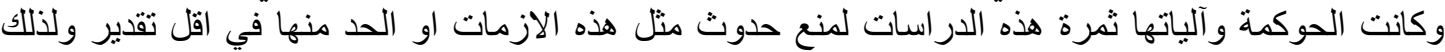

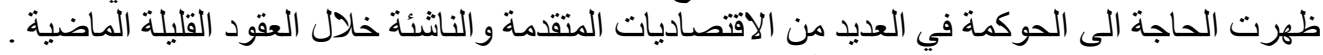

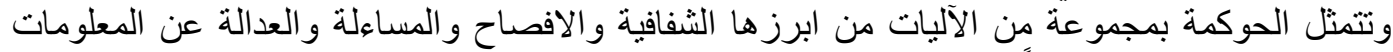

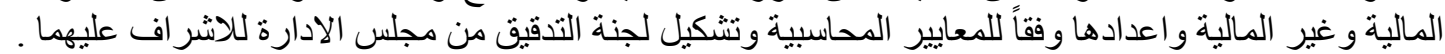

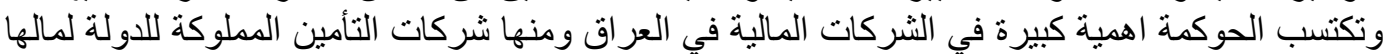

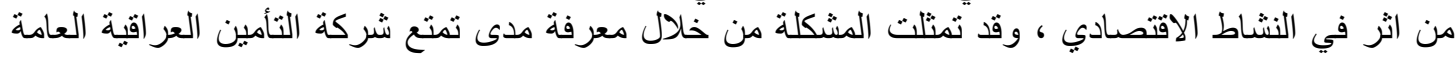

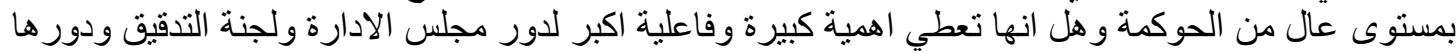

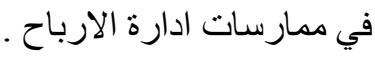

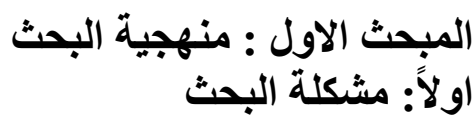

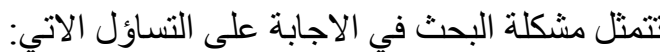

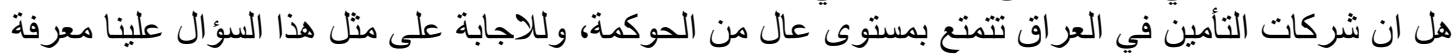

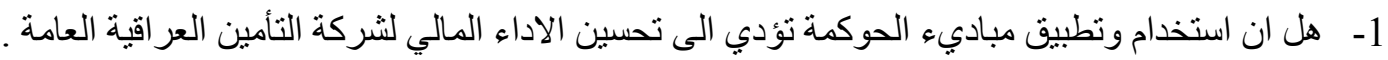

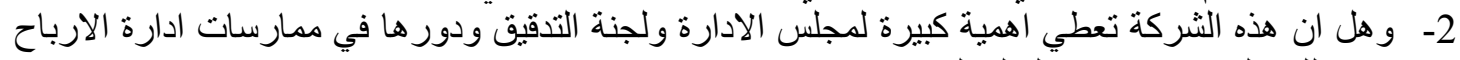

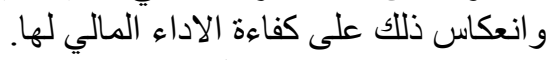

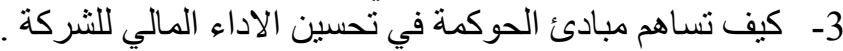

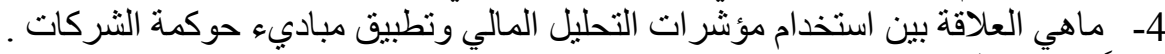

ثانياً: فرضية البحث

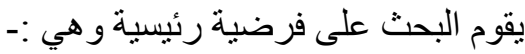

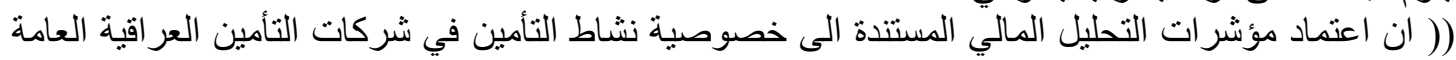

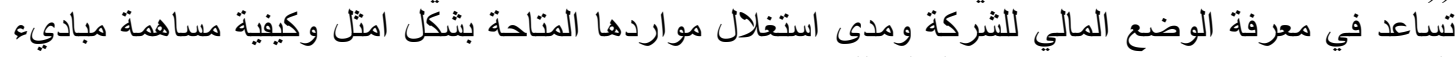

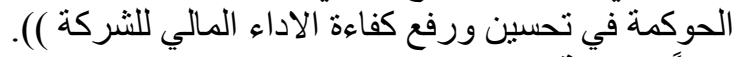

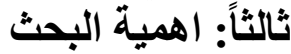

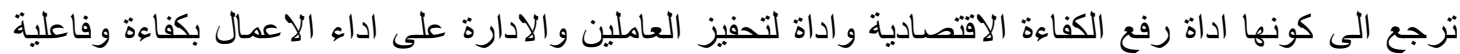

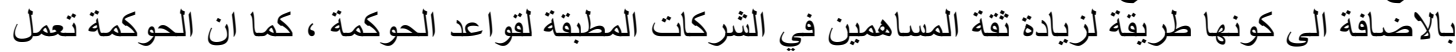

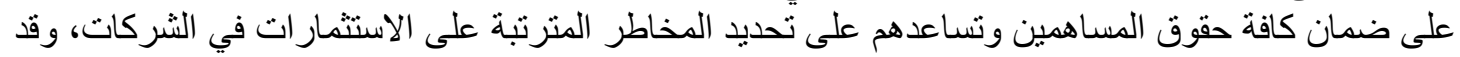

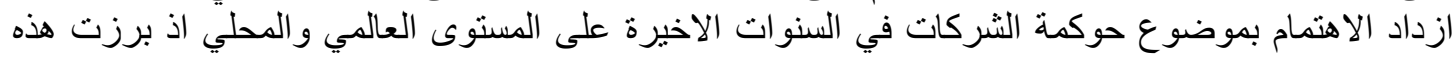

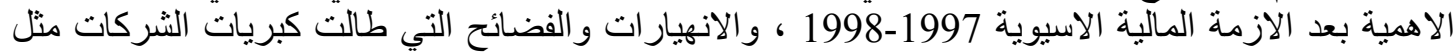

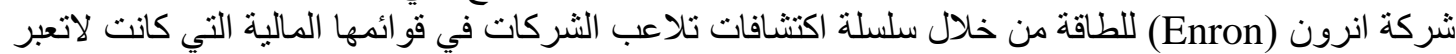

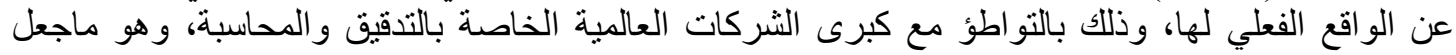

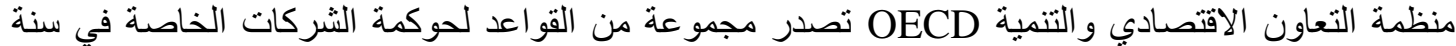
2004 ولحوكمة الثركات المملوكة للدولة في سنة 2005. 


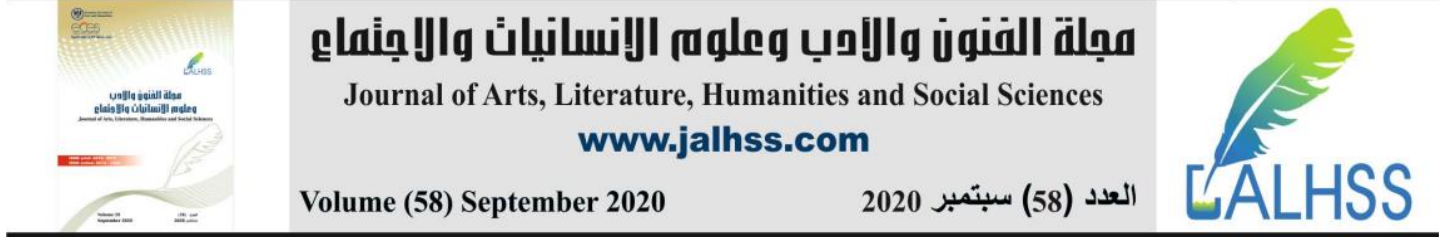

وان الوعي بمفاهيم الحوكمة و آلياتها وتطبيقاتها يؤدي الى تحقيق قدر اكبر من الثفافية و العدالة وبالتالي حماية

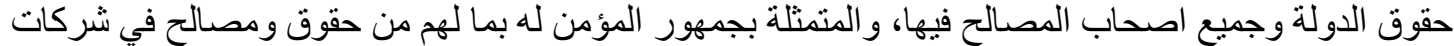

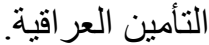

رابعا: هدف البحث البث

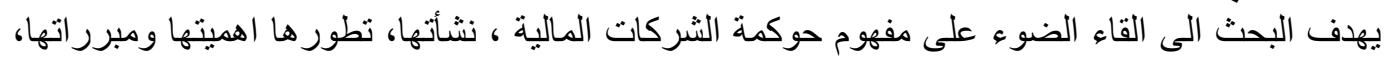

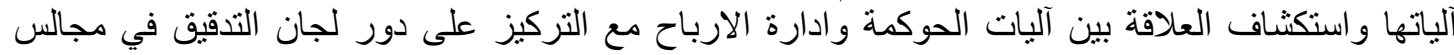

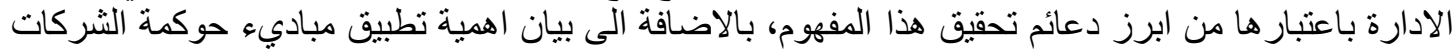

في البيئة العر اقية لتحسين الاداء الاعناء الاداري و المالي.

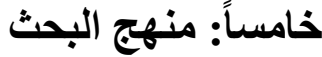

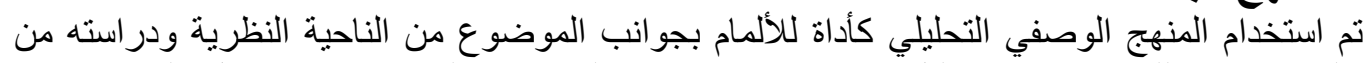

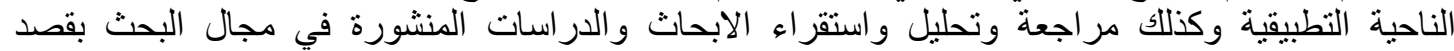

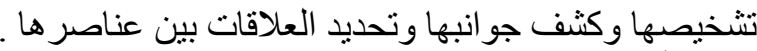

سادساً: حدود البحث

أـ الحدود الموضودية : اقتصر البحث على تحليل الاطار المفاهيمي للحوكمة الرشيدة في الثركات المالية ،

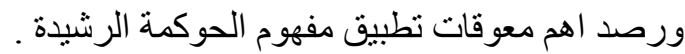
بــ الحدود الزمانية : اقتصر البحث على شركة التأمين العر اقية العامة كونها من الثركات الر ائدة في العراق .

المبحث الثاني : دراسات سابقة تناول العديد من الباحثين موضوان التوع حوكمة الثركات لما له من اهمية كبيرة في اداء الثركات ودفع عملية التنمية

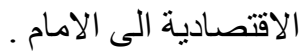
• در اسة (Beltratti 2005) : هدفت الدراسة الى فهم علاقة حوكمة الثركات و المسؤولية الاجتماعية

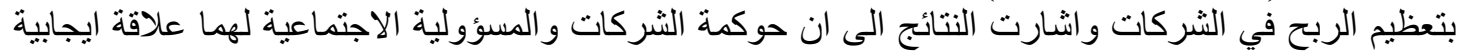

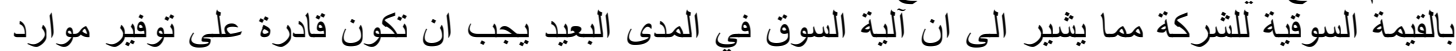

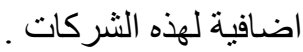

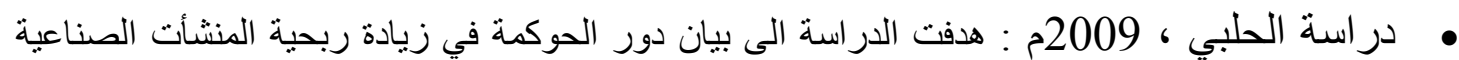

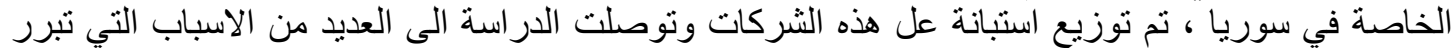

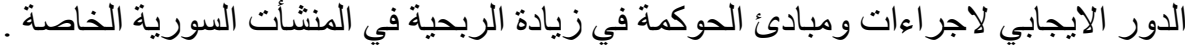

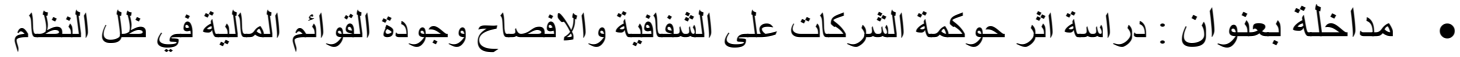

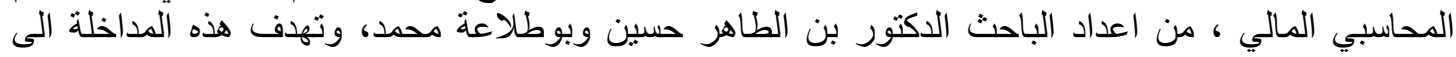

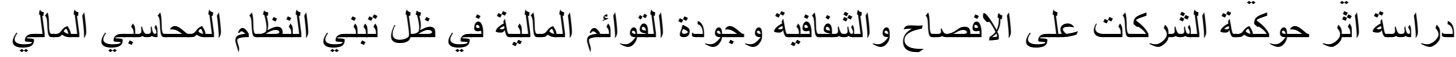

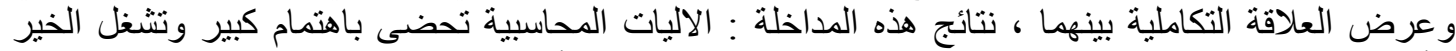

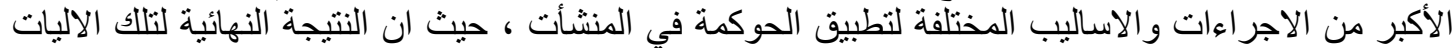

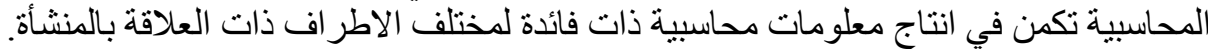

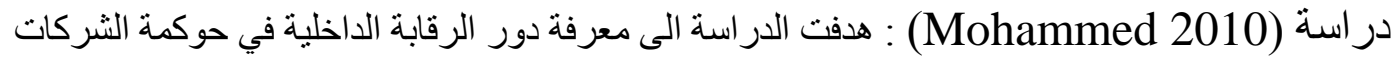

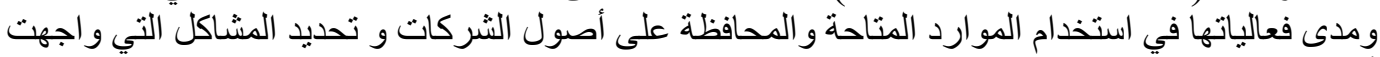

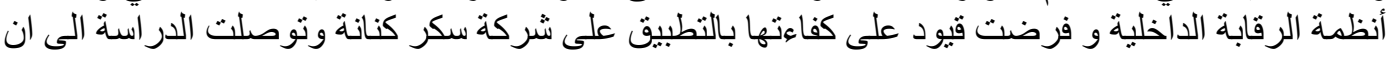

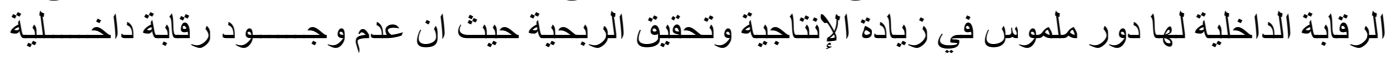
ومر اجعة دورية يؤدي إلى ضعف الأل الاداء و الكفاءة.

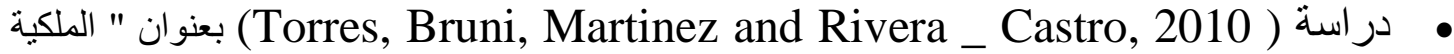

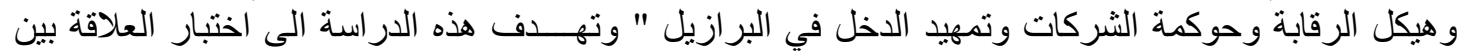

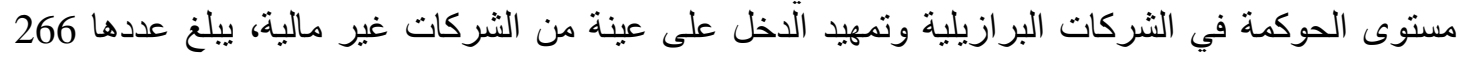




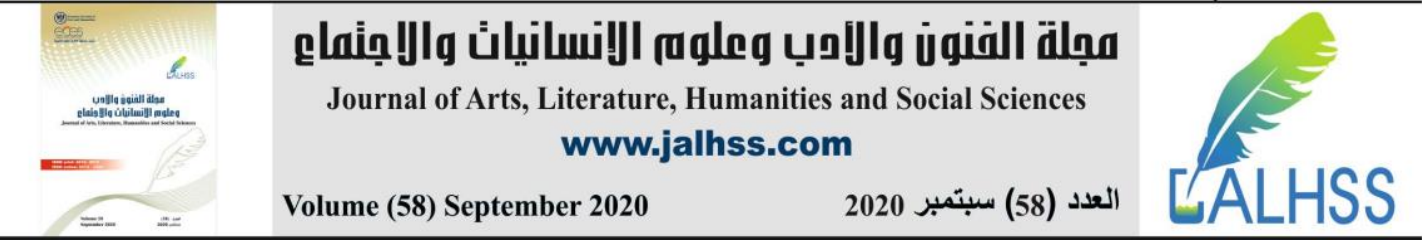

شركة مسجلة في سوق (saopaule) للاوراق المالية للفترة من 2007 - 1998 وقد استخدمت هذه الدراسة

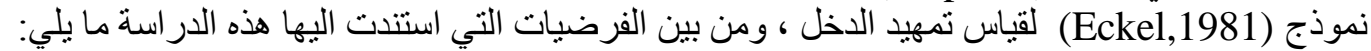

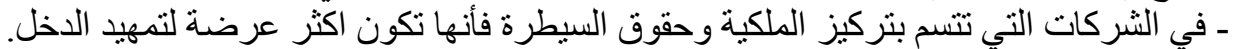

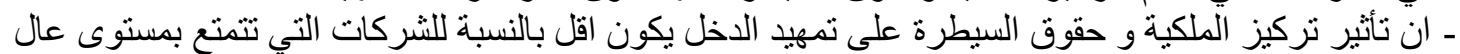
للحوكمة.

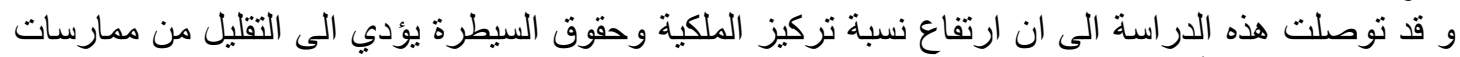
تمهيد الدخل، وان تأثير تركيز الملكية و حقوق السيطرة على تمهيد الدخل يكون اقل في الثركية الثركات التي يكون فيها مستوى الحوكمة جيدا. في ضوء الدر اسات السابقة تشير الباحثة الى الملاحظات الاتية: ان حوكمة الثركات تؤدي الى تعظيم الربح.

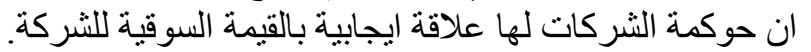

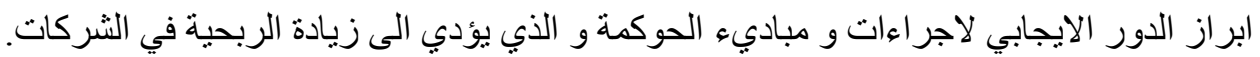

\section{المبحث الثالث: الاطار النظري للبحث}

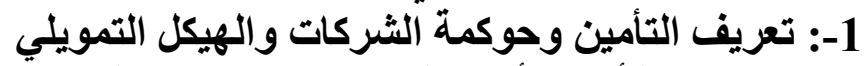

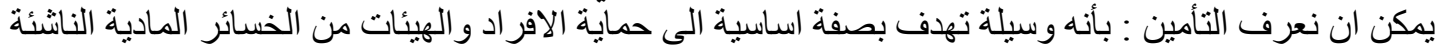

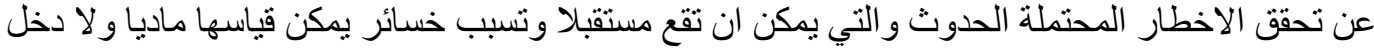

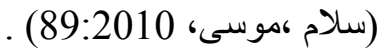

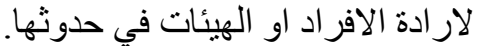

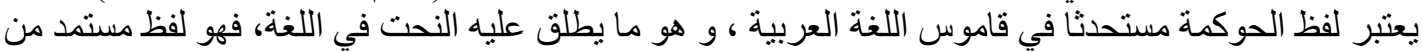

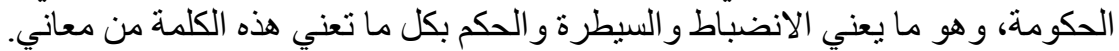

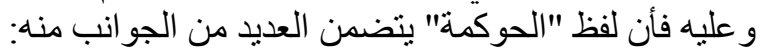

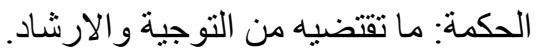

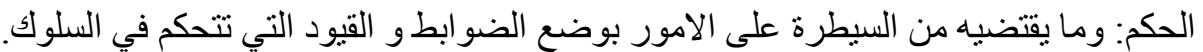

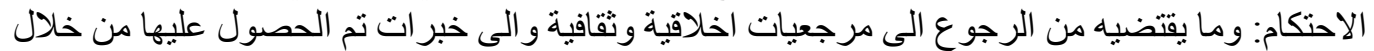

تجارب سابقة. التحاكم: طلبا للعدالة خاصة عند انحر اف سلطة الادارة وتلاعبها بمصالح المساهمين.

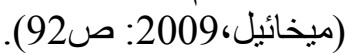

وبذلك يمكن تعريف الحوكمة: بانها نظام متكامل للرقابة المالية و الغير مالية الذي عن طريقه يتم ادارة الثركة

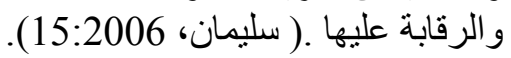
و عرف النعيمي و التميمي هيكل التمويل : على انه هيكل مصادر التمويل او جانب المطلوبات وحق الملكية في

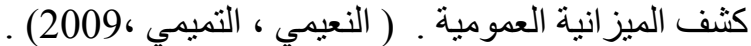
وهنا ترى الباحثة ان الحوكمة مرتبطة بالادارة الرشيدة، حيث ان الحوكمة تتضمن مجمو عة من الآليات و النظم

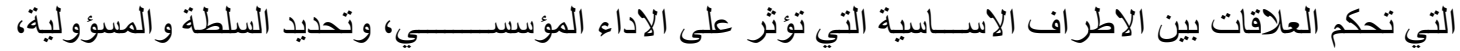

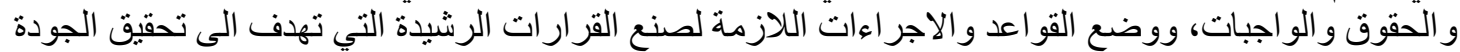

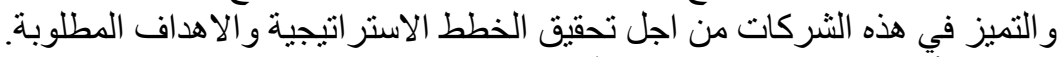

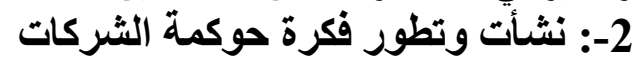

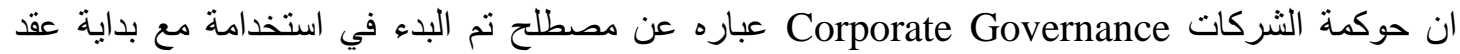

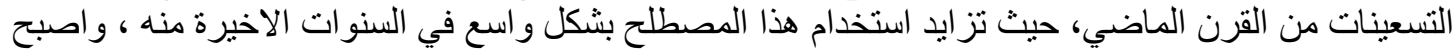

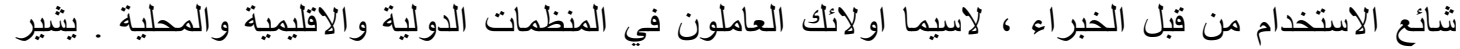

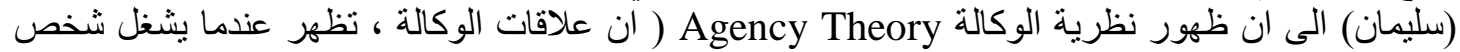

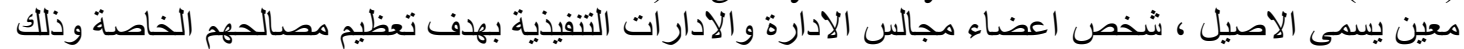

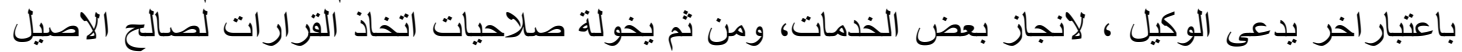

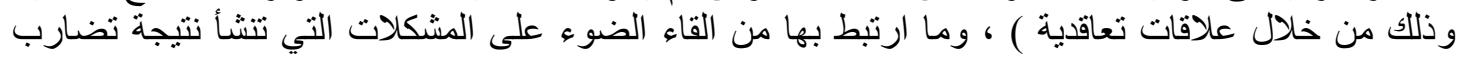




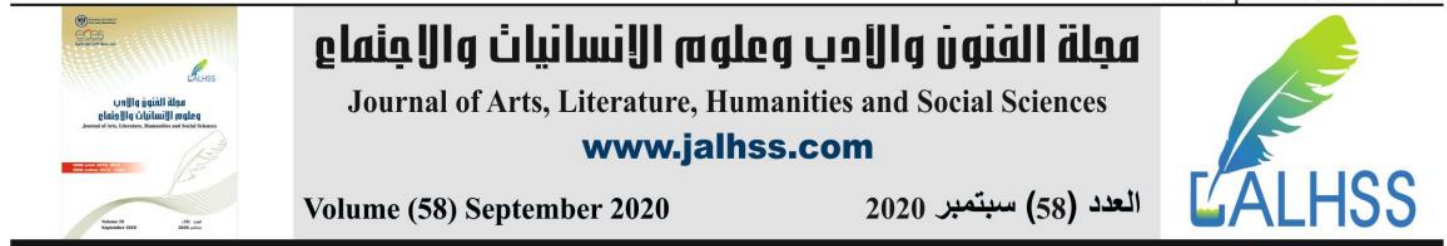

المصالح بين اعضاء مجالس ادارة الثركات وبين المالكين ادى الى زيادة الاهتمام و التفكير في ضرورة والحئ وجود

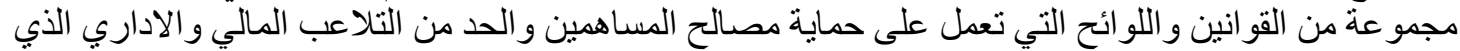

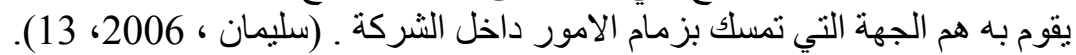

الاطراف الرئيسية في الحوكمة

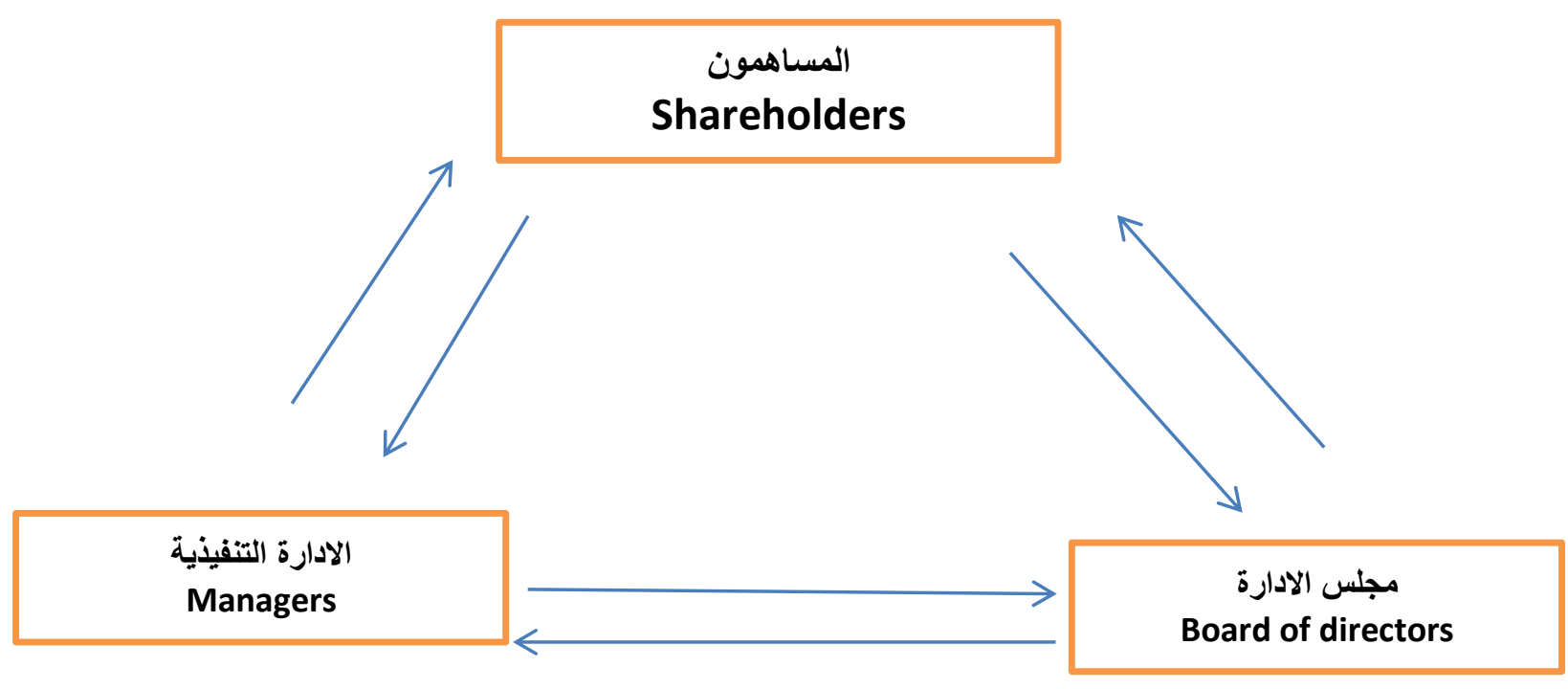

تقوم الحوكمة بتظظيم وتقسيم المسؤوليات والحقوق بين ثلاثة اطر اف رئيسية )

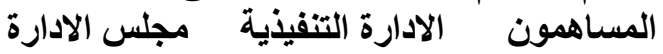

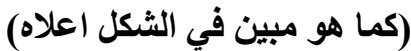

المصدر - اساسيات الحوكمة: مصطلحات ومفاهيم، سلسلّة النشرات التثقيفية لمركز ابو ظبي للحوكمة)) .

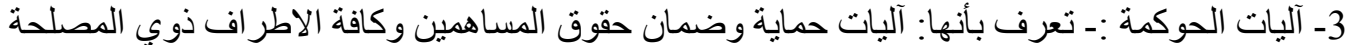
المرتبطين بأعمال الثركة عبر احكام الرقابة والسيطرة على الداء آلئ ادارة الثركة ، ومر اقبة الحسابات (حمودة ،

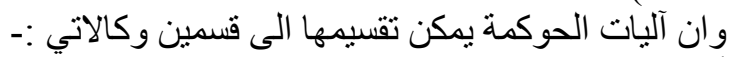

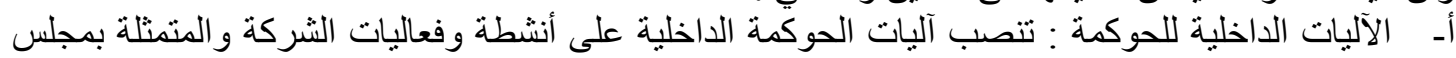

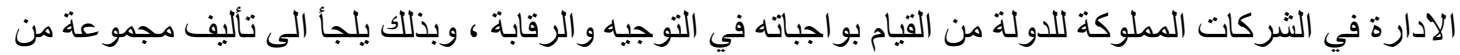

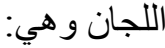

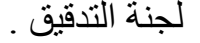

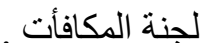

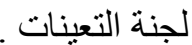

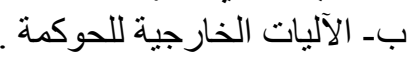

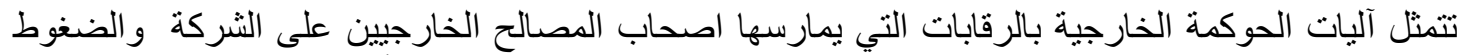

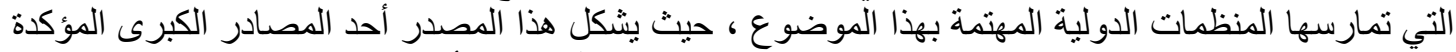
لضغط هائل من اجل تطبيق قو اعد الحوكمة ومن الامثلة على هذه الآليات ما يأتي :- 
توفير قو اعد حوكمة الثركات و الاطار التنظيمي الذي بمكن الثركة من تحديد اهدافها وكيفية تحقيقها .

6- مباديء الحوكمة :- خلصت منظمة التعاون الاقتصادي والتنمية (2004) الى وضع ستة مباديء رئيسية

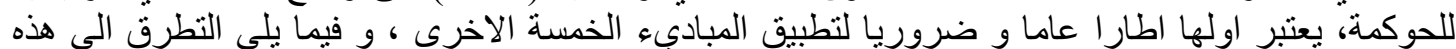

و هنا ترى الباحثة ان الحوكمة تعمل على تنظيم العلاقة بين كل من المساهمين ومجلس الادارة و الادارة التففيذية بحيث تحدد الحوكمة مسؤوليات كل طرف وحقوقه وتهدف الحوكمة الى تعزيز مباديء الثفافية والمساءلة و المسؤولية والعدالة من خلال وضع مجموعة من القو اعد التي يجب على الثركة الالتز ام و التقييد بها.

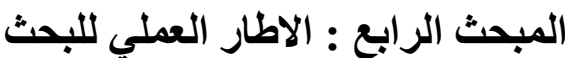

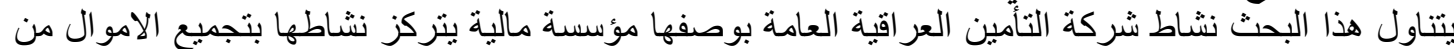

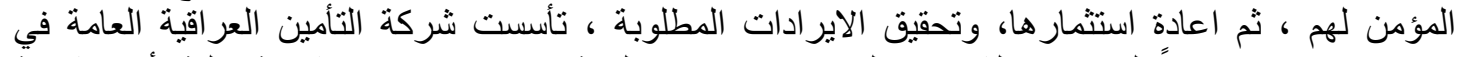

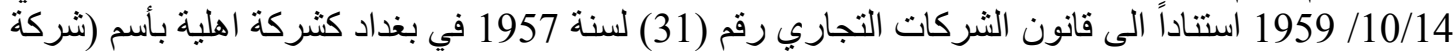

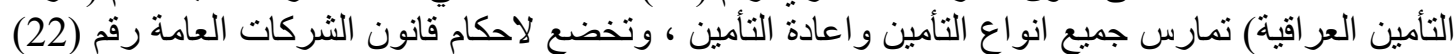

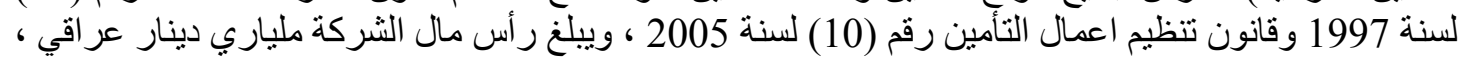

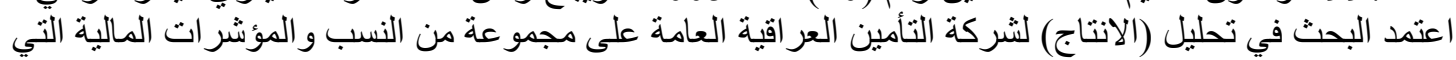

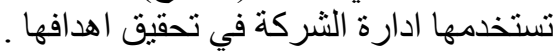




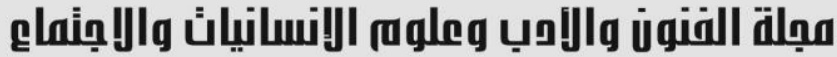

\author{
Journal of Arts, Literature, Humanities and Social Sciences
} www.jalhss.com

• تطور مجموع (الاتتاج) خلال السنوات (2011-2015)

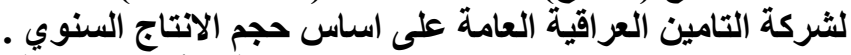
(المبالغ بآلاف الدنانير)

جدول (1) متوسط حجم الانتاج (الاقَّاط) لشركة التأمين العراقيّة العامة ولئية وللمدة (2011-2015 )

\begin{tabular}{|c|c|}
\hline (الاتتاج) اقساط التأمين المتحققة & السنوات \\
\hline 24529277 & 2011 \\
\hline 43354051 & 2012 \\
\hline 51275288 & 2013 \\
\hline 60370630 & 2014 \\
\hline 63468048 & 2015 \\
\hline
\end{tabular}

\begin{tabular}{|c|c|c|c|}
\hline $\begin{array}{r}\text { نسبة التحقق } 2: 1) \\
\text { (2:1 }\end{array}$ & صافي الربح المتحقة السابقة & السنة الحالية الربح اللستحقةق & السنة \\
\hline$\% 9,38$ & 2793873 & 262296 & 2011 \\
\hline$\% 24,18$ & 3056169 & 739250 & 2012 \\
\hline$\% 28$ & 3795419 & 1056883 & 2013 \\
\hline$\% 46$ & 4852302 & 2220215 & 2014 \\
\hline$\% 52$ & 7072517 & $3678837-$ & 2015 \\
\hline
\end{tabular}

المصدر: الميز انية العمومية لثركة التأمين العر اقية العامة.

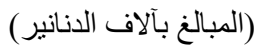

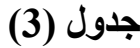

\begin{tabular}{|r|r|r|r|r|r|r|}
\hline شركة التأمين العر اقية & \\
\hline $32-$ & 2015 & 2014 & 2013 & 2012 & 2011 & \\
\hline
\end{tabular}




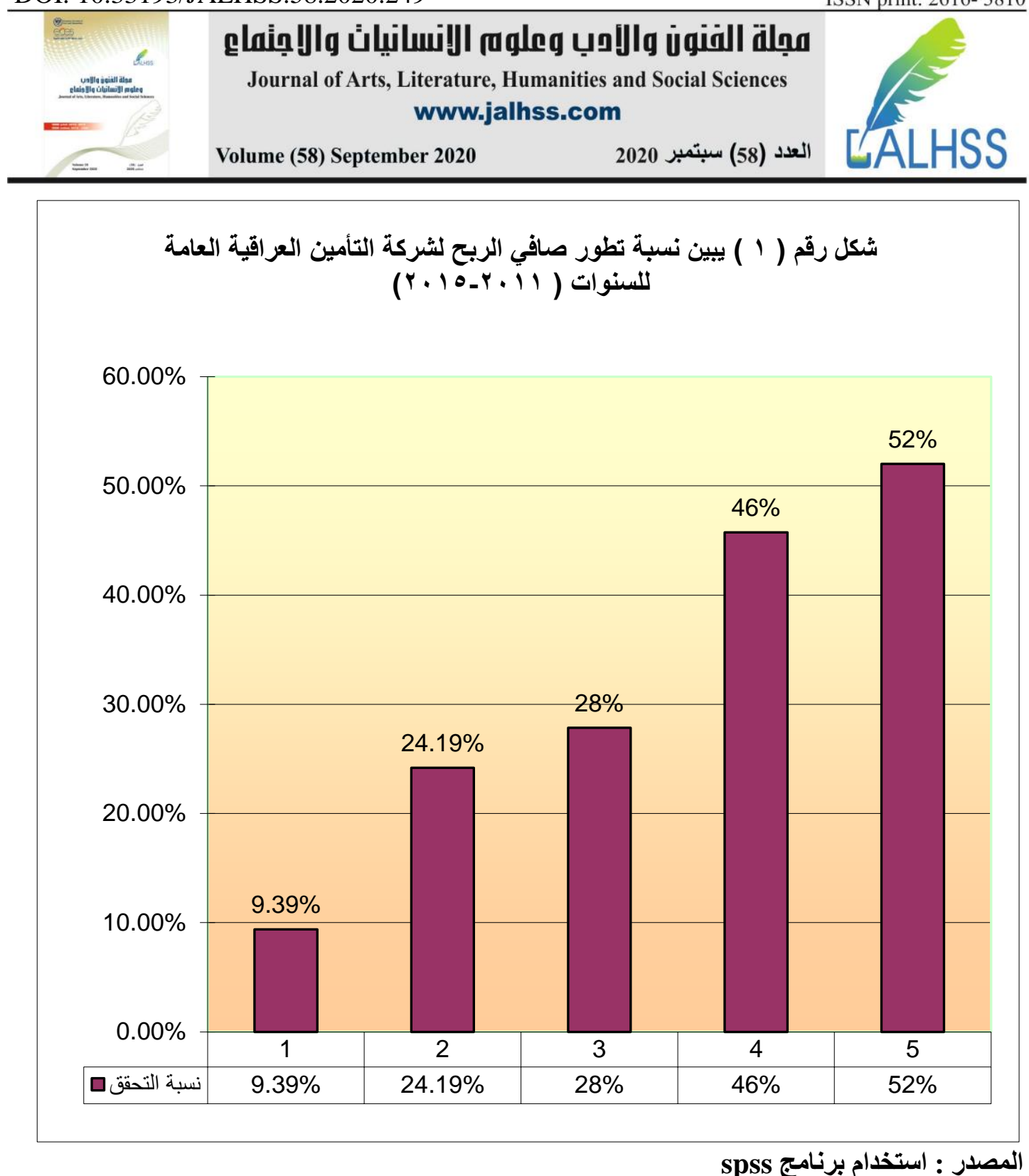

جدول (4) نسبة تحقيق عوائد الاستثمار لشركة التأمين العراقية العامة وللمدة (2011-2015) (المبلغ بآلاف الدنانير )

\begin{tabular}{|c|c|c|c|}
\hline $\begin{aligned} \text { نسبة التحقق } & \text { ن } 2: 1 \text { (2:1) }\end{aligned}$ & عو ائد الاستثمار المخططة خلال السنة & عوائد الاستثمار المتحققة خلال السنة & السنة \\
\hline$\% 97$ & 1700000 & 1652786 & 2011 \\
\hline$\% 86$ & 2000000 & 1714150 & 2012 \\
\hline$\% 104$ & 2300000 & 2394596 & 2013 \\
\hline$\% 105$ & 2400000 & 2522864 & 2014 \\
\hline$\% 113$ & 2650000 & 2994705 & 2015 \\
\hline
\end{tabular}

المصدر: الميز انية العمومية لشركة التأمين العر اقية العامة. 
DOI: $10.33193 / J A L H S S .58 .2020 .249$

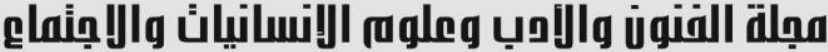

Journal of Arts, Literature, Humanities and Social Sciences www.jalhss.com

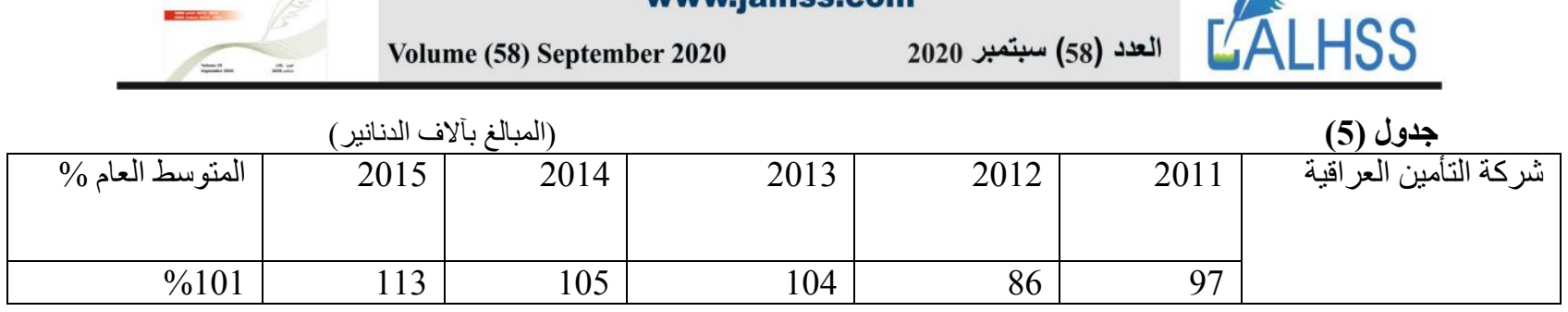

شكل رقم ( r ) يبين نسبة تحقيق عوائد الاستثمار لثركة التأمين العراقية العامة

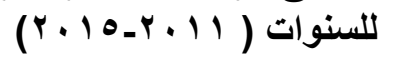

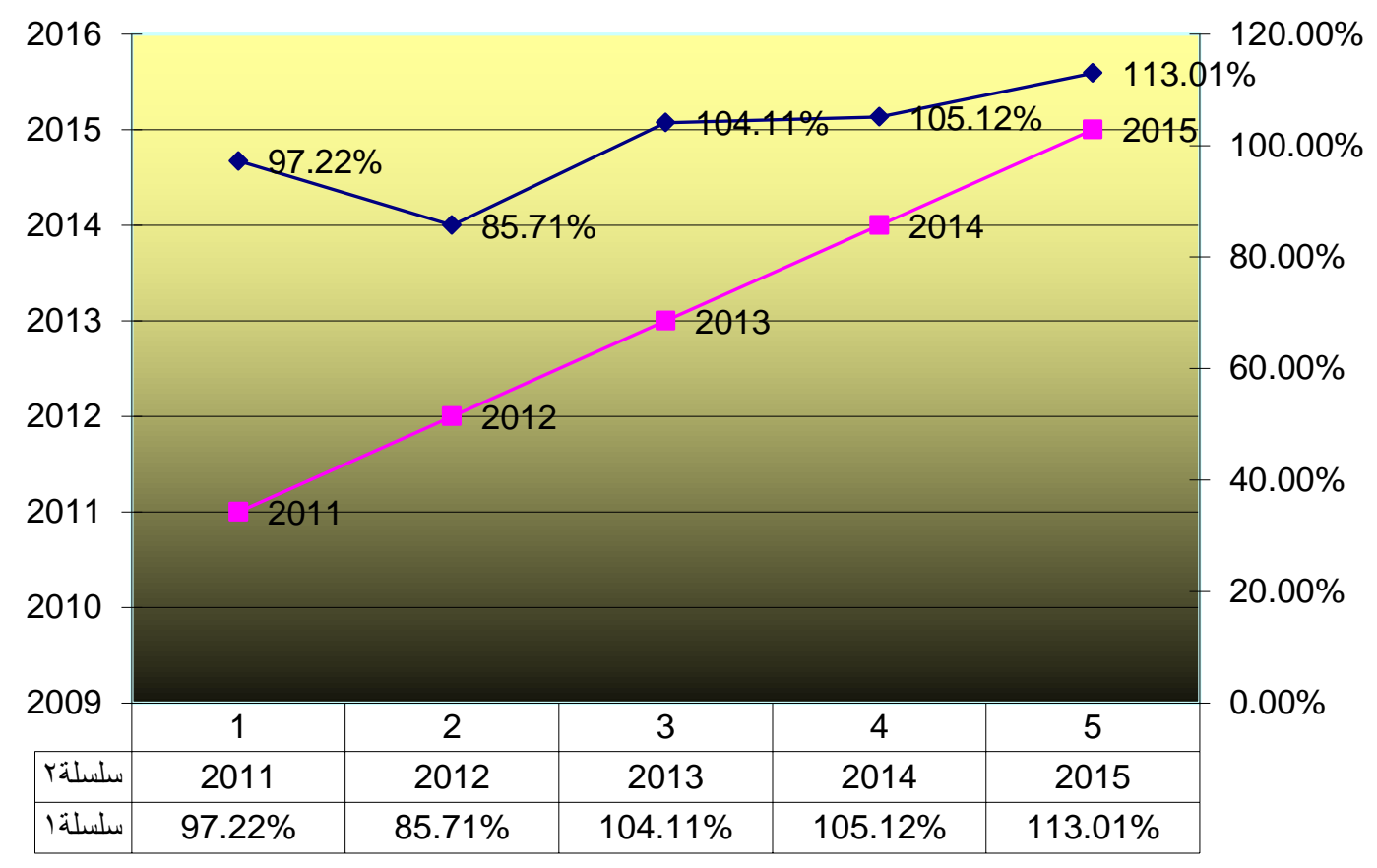

المصدر : استخدام برنامج (6) معدل جذول ( 6) معدل العائد على الموجودات لثركة التأمين العراقية العامة و للمدة (2011 - 2015) (المبالغ بآلاف الدنانير )

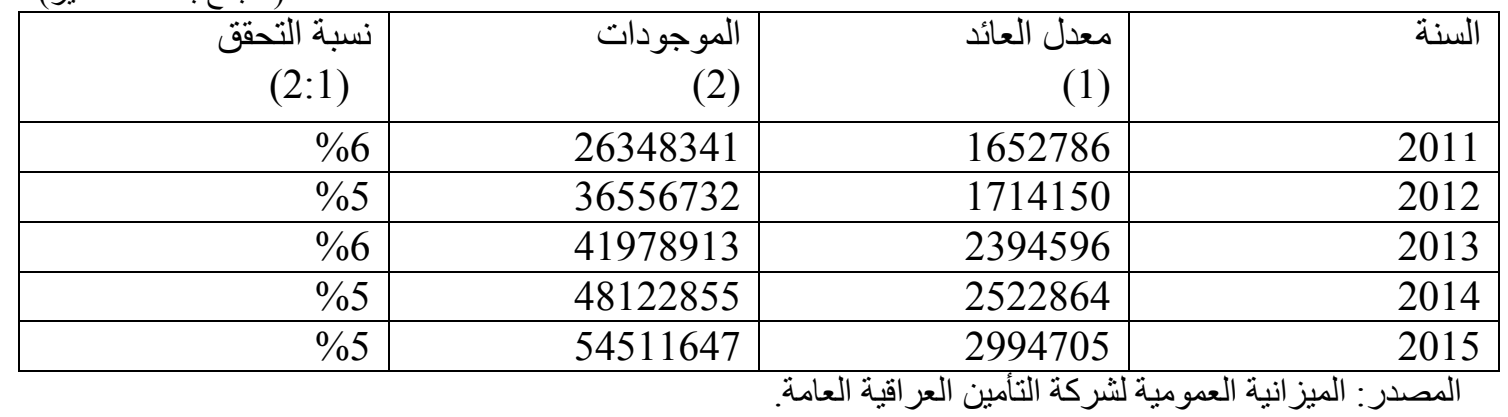




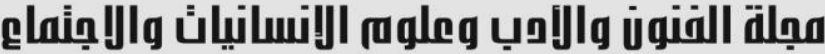

\begin{tabular}{|c|c|c|c|c|c|c|}
\hline 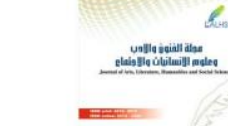 & \multicolumn{4}{|c|}{$\begin{array}{l}\text { Journal of Arts, Literature, Humanities and Social Sciences } \\
\text { www.jalhss.com }\end{array}$} & & \multirow{2}{*}{ ALHSS } \\
\hline$=-\quad=$ & \multicolumn{3}{|c|}{ Volume (58) September 2020} & \multicolumn{2}{|c|}{ العدد (58) سبتمبر 2020} & \\
\hline & 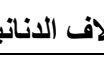 & & & & & جدول (7) \\
\hline \% & 2015 & 2014 & 2013 & 2012 & 2011 & شركة التأمين \\
\hline$\% 5,4$ & 5 & 5 & 6 & 5 & 6 & العامة \\
\hline
\end{tabular}

\section{شكل رقم ( r ) يبين معدل العائد على الموجودات لشركة التأمين العراقية العامة}

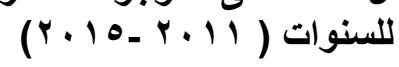

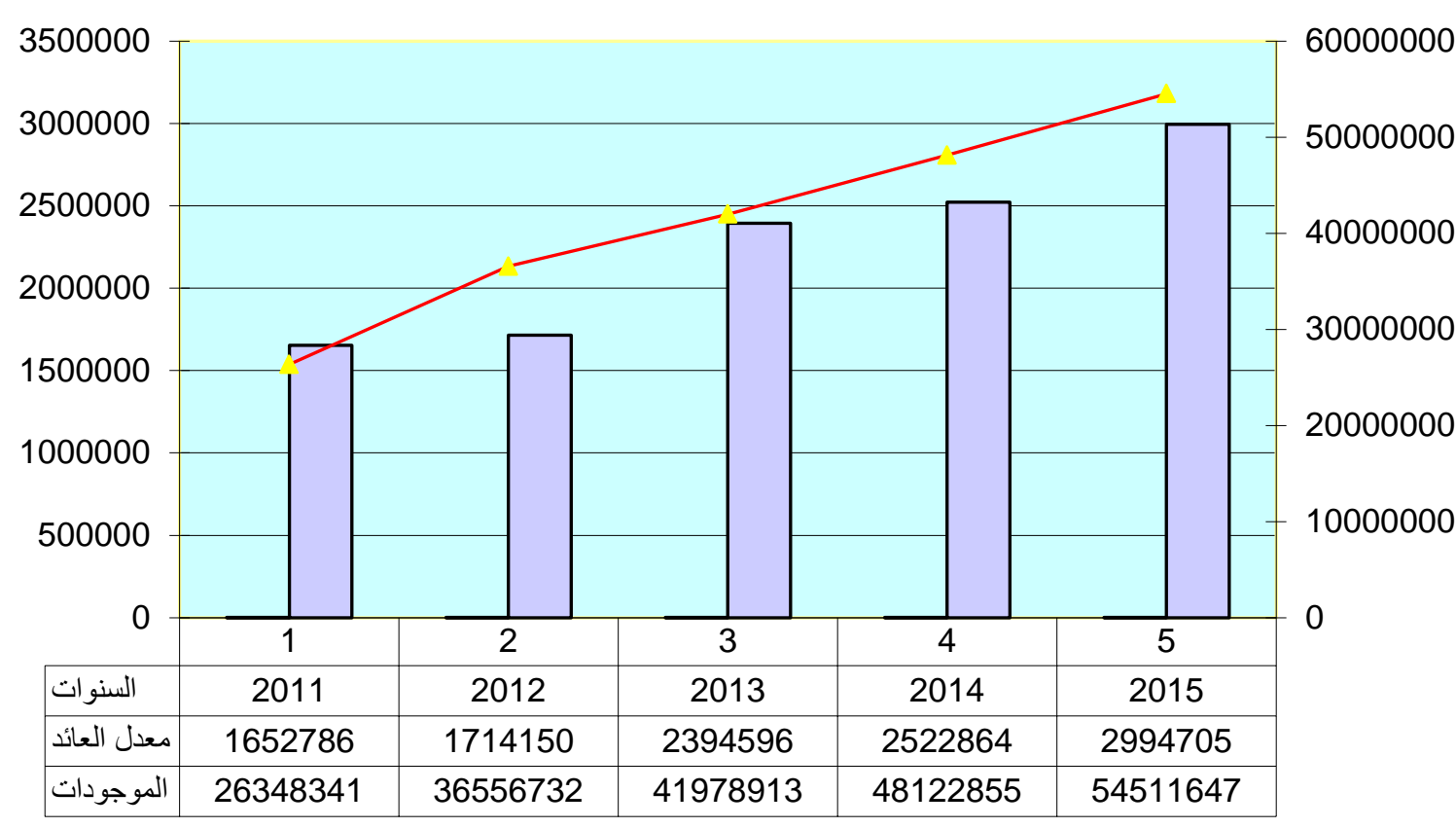

SpSS المصدر : استخدام برنامج (المبالغ بآلاف الدنانير )

جدول (8) نسبة تحقيق صافي الربح لشركة التأمين العراقي العامة وللمدة (2011-2015) )

\begin{tabular}{|c|c|c|c|}
\hline نسبة التحقيق (2:1) & صافي الربح المخطط & صافي الربح الفعلي & السنة \\
\hline 102 & 3007750 & 3056169 & 2011 \\
\hline 105 & 3607700 & 3795419 & 2012 \\
\hline 119 & 4069700 & 4852302 & 2013 \\
\hline 134 & 5274500 & 7072517 & 2014 \\
\hline 153 & 2222500 & 3393680 & 2015 \\
\hline
\end{tabular}

المصدر : الميز انية العمومية لشركة التأمين العر اقية العامة. 


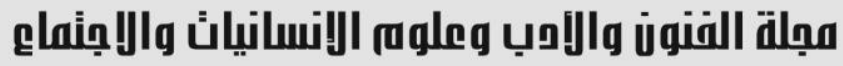

Journal of Arts, Literature, Humanities and Social Sciences www.jalhss.com

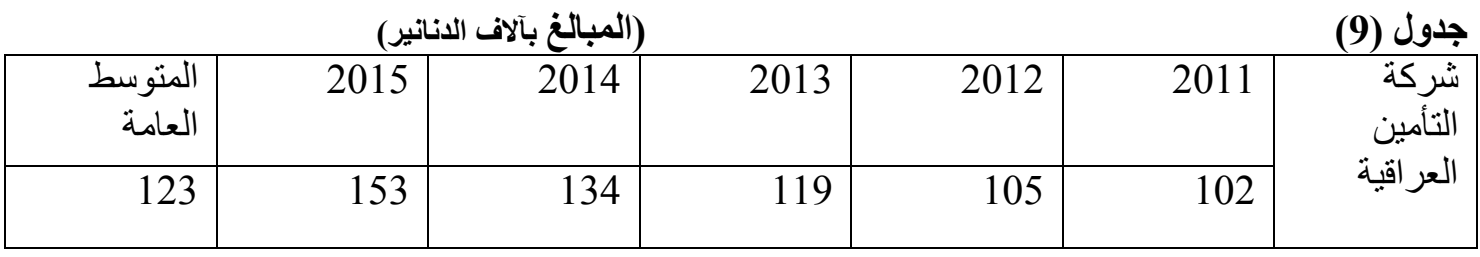

شكل رقم (4) يبين نسبة تحقيق صافي الربح الفعلي والمخطط

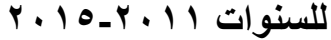

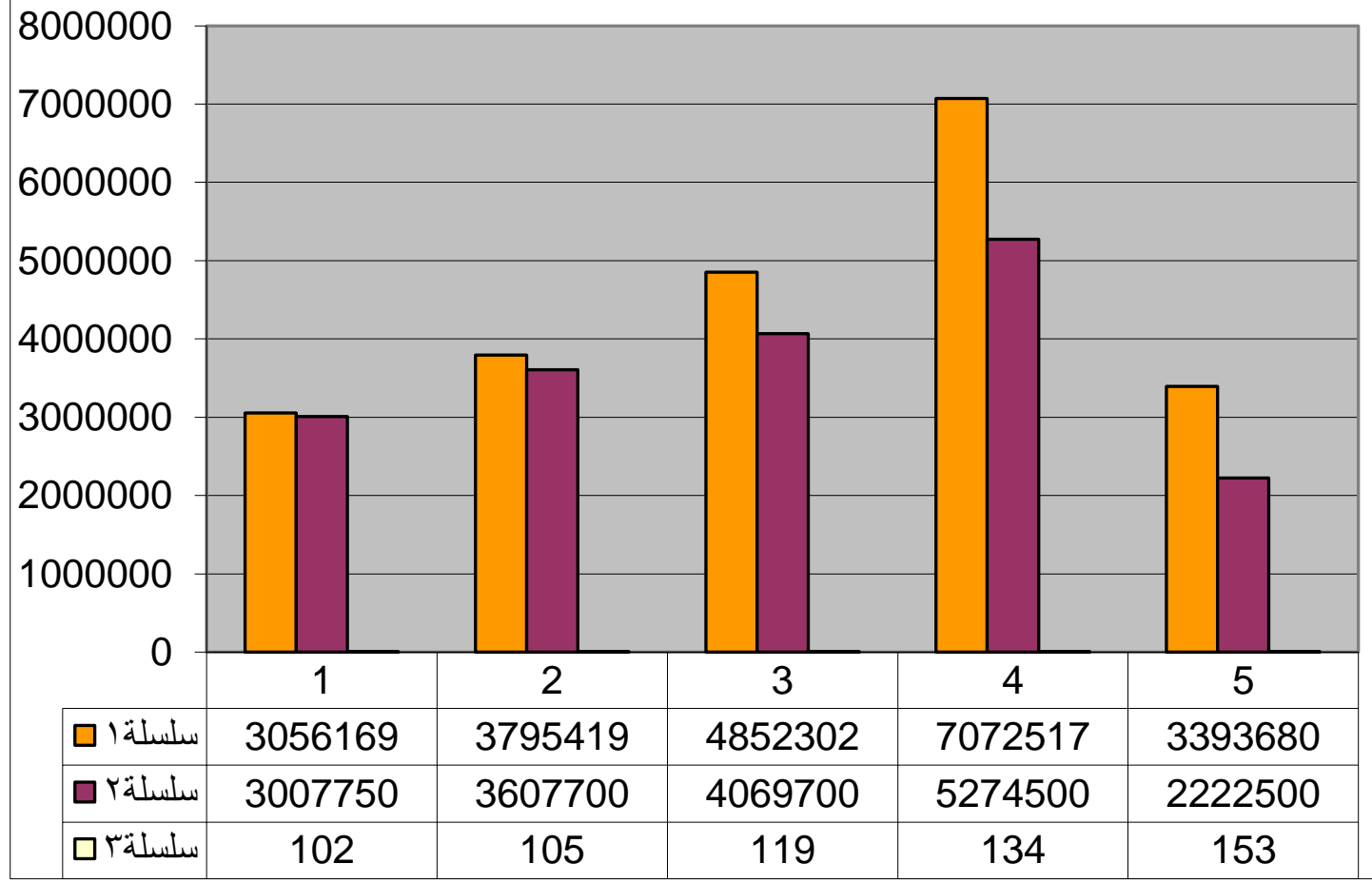

المصدر : استخدام برنامج Spss

جدول (10) معدل العائد على الاموال المتاحة لشركة التأمين العراقية العامة وللمدة (2011 - 2015) (المبالغ بآلاف الدنانير)

\begin{tabular}{|r|r|r|r|}
\hline نسبة التحقيق (2:1) & (السنة & \\
& (المساهوع الودائع+ حقوق & & \\
\hline 32 & 9562643 & 3056169 & 2011 \\
\hline 24 & 15643703 & 3795419 & 2012 \\
\hline 19 & 25247365 & 4852302 & 2013 \\
\hline 18 & 38680205 & 7072517 & 2014 \\
\hline 9 & 39109271 & 3393680 & \\
\hline
\end{tabular}

المصدر : الميز انية العمومية لشركة التأمين العر اقية العامة. 


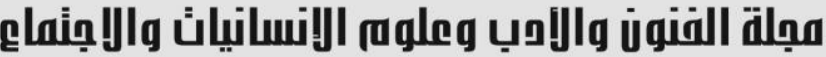

\author{
Journal of Arts, Literature, Humanities and Social Sciences
} www.jalhss.com

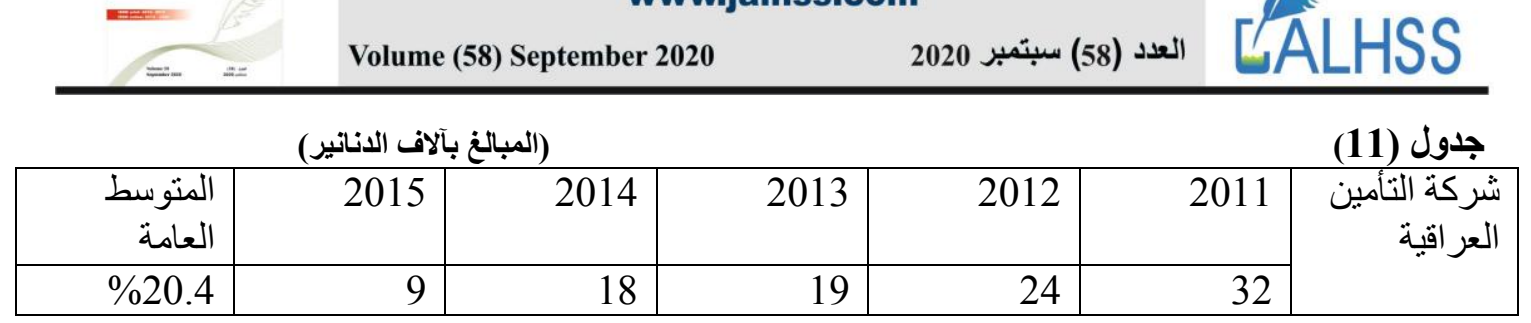

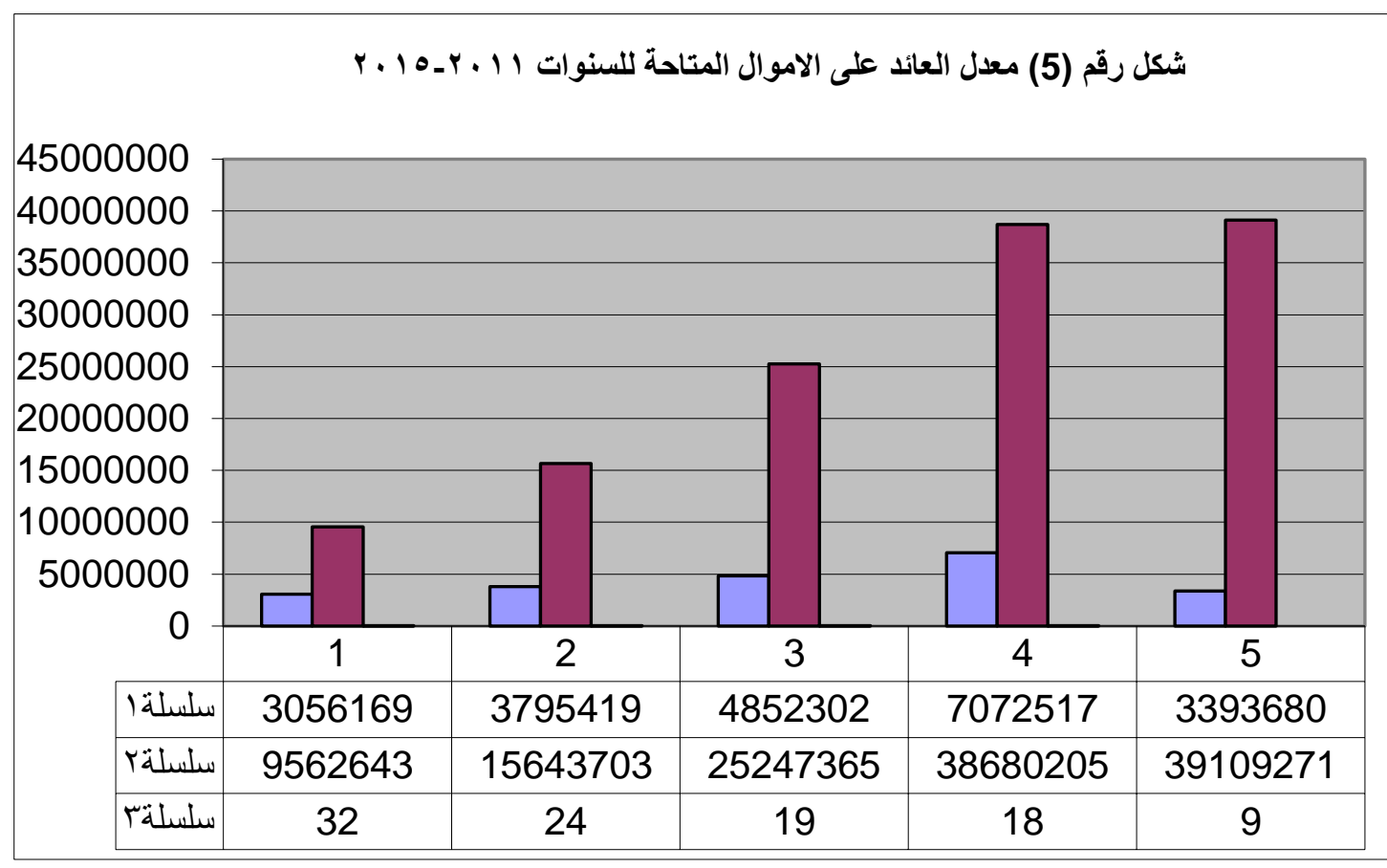

spss المصدر : استخدام برنامج

\section{التحليل الاحصائي لتطور (الاتتاج) لشركة التأمين العراقية العامة}

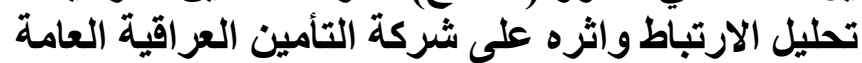

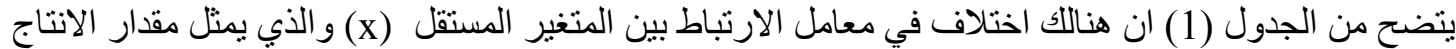

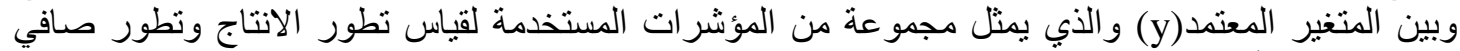

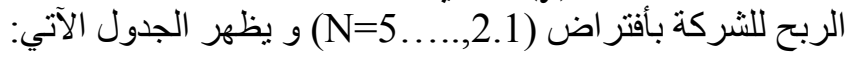




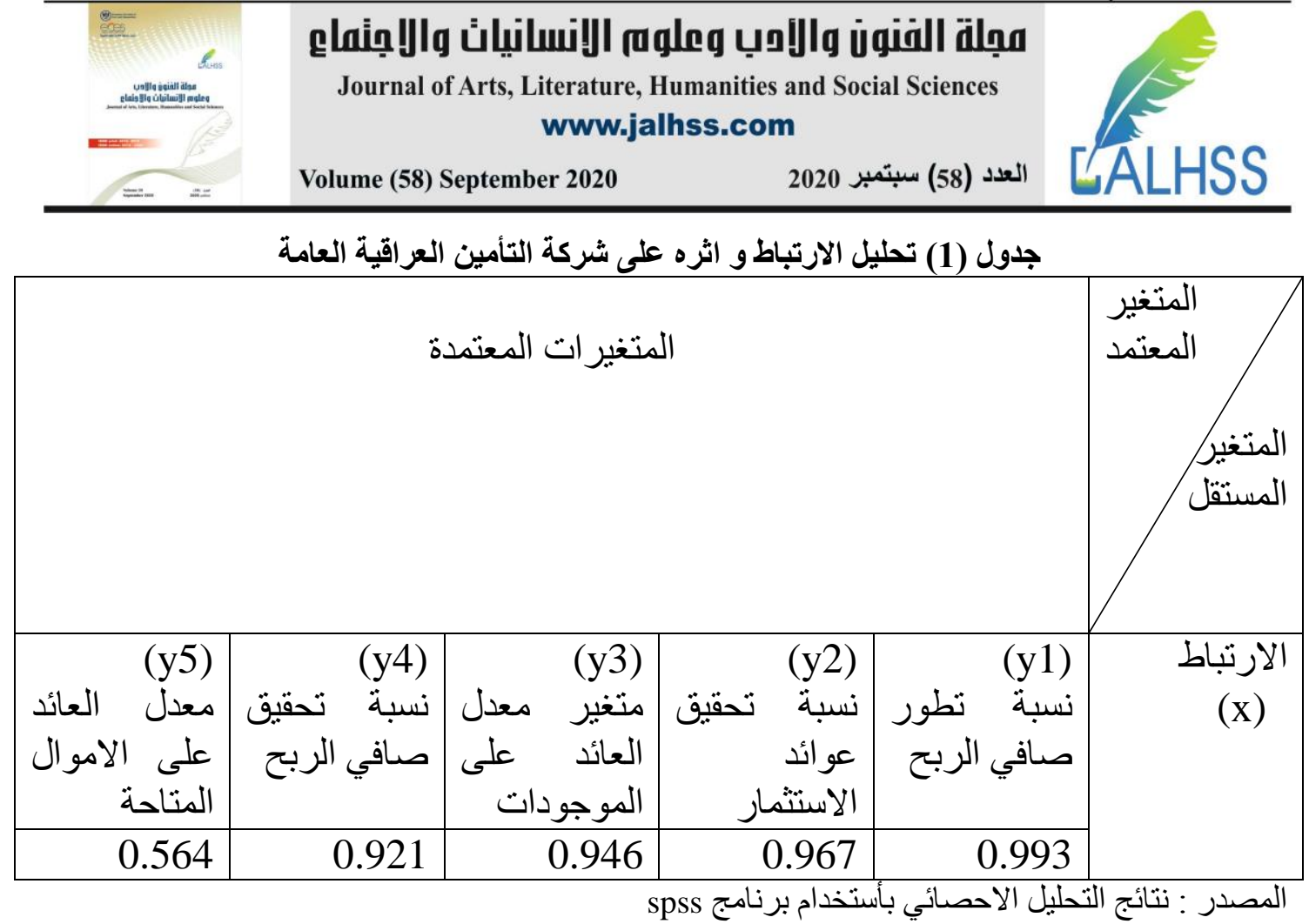

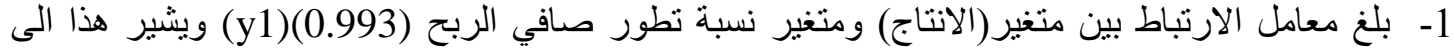

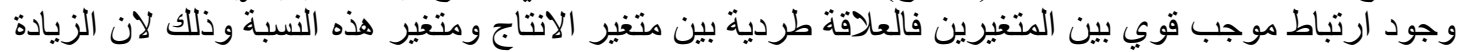

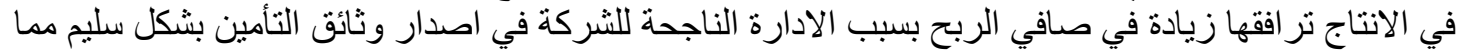

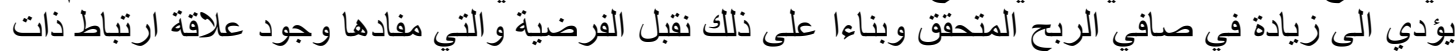

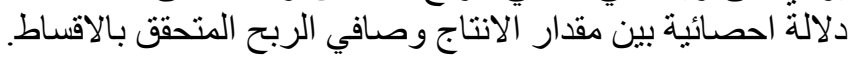

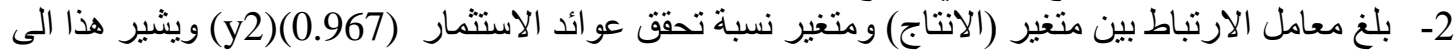

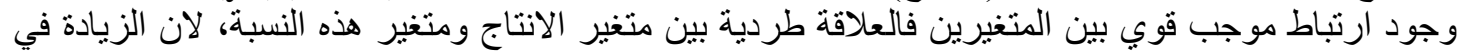

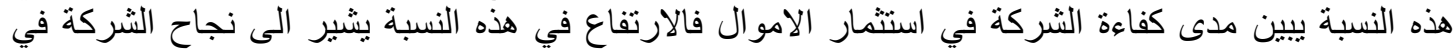

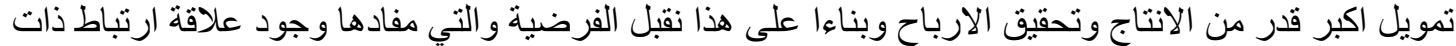

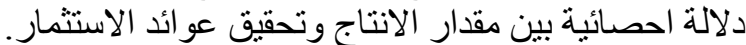

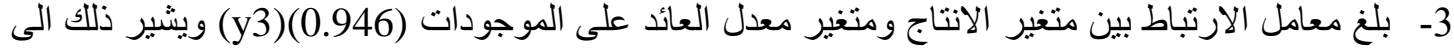

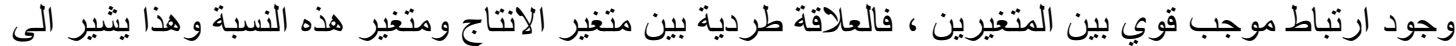

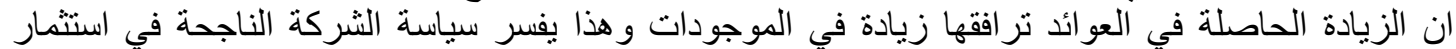

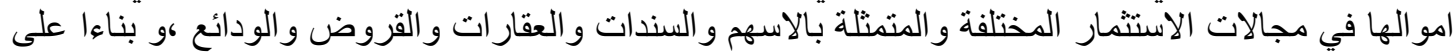

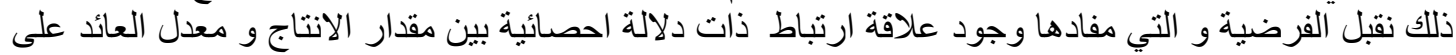

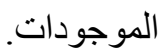

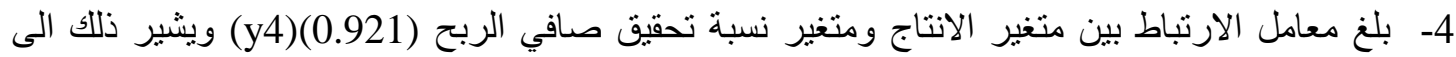

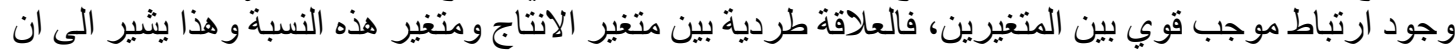

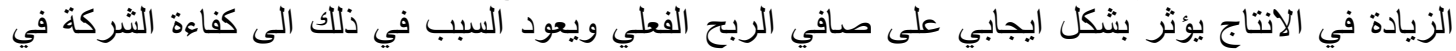

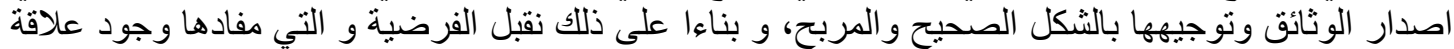

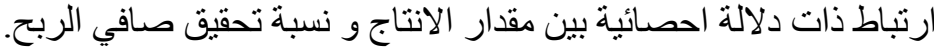

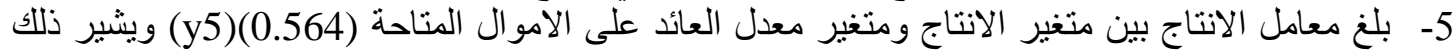

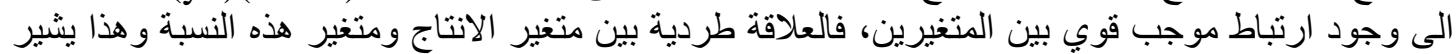

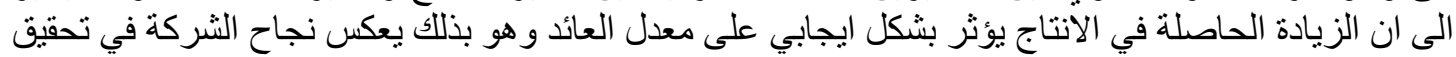

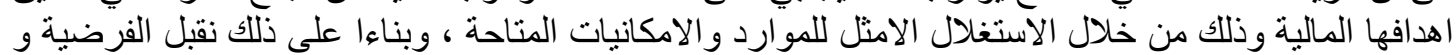

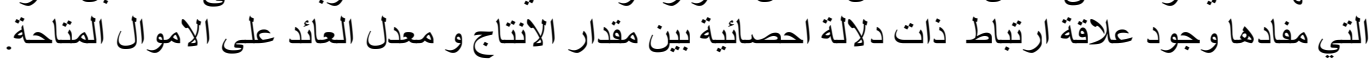




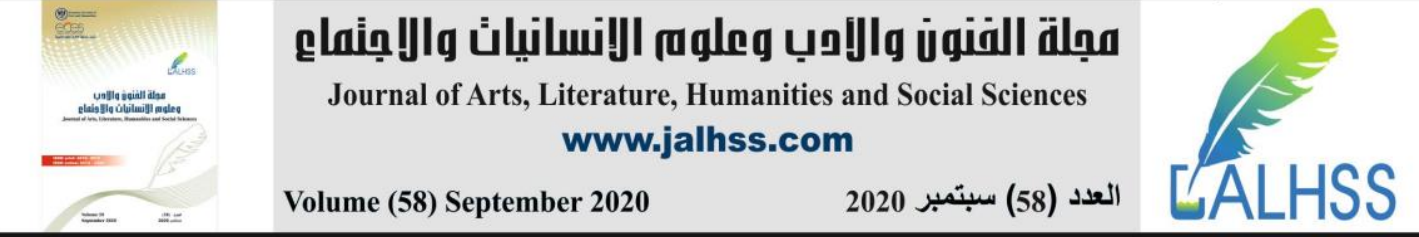

الاستنتاجات والتوصيات

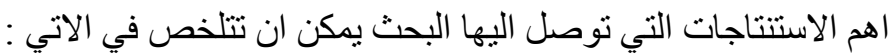


الاستثمار وزيادة التدفق النقدي للشركة.

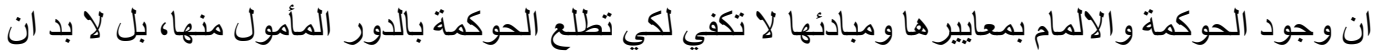
ير افق ذللك كله تطبيق حازم لها و الاحتكام الى مبادئها. • على الثركات المالية الاهتمام بلجان التدقيق في مجلس الادارة بأعتبار ها ابرز دعائم تحقيق هذا المفهوم

الجديد وهو الحوكمة المالية.

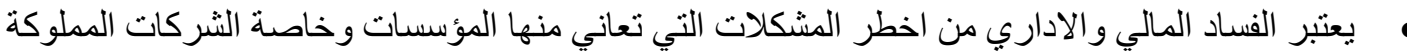

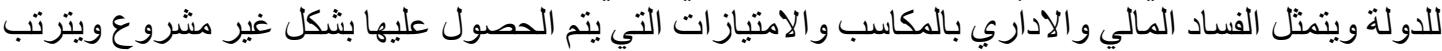

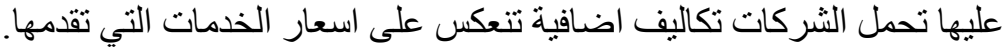

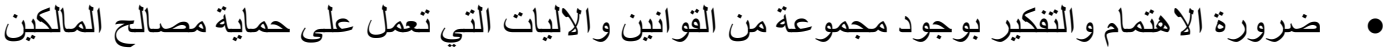

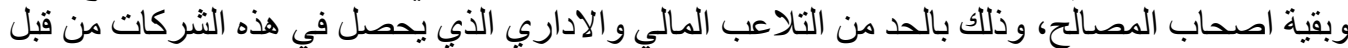
الادار ات التنفيذية.

ان تطبيق آليات الحوكمة وقو اعدها من قبل الثركات المملوكة للدولة يؤدي الى الحد من الفساد المالي و الاداري فيها وزيادة كفاءة ادائها.

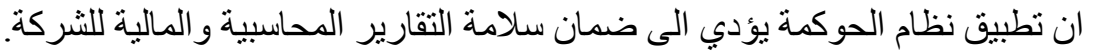
و توصل البحث الى جملة توصيات اهوبها: الهيا:-

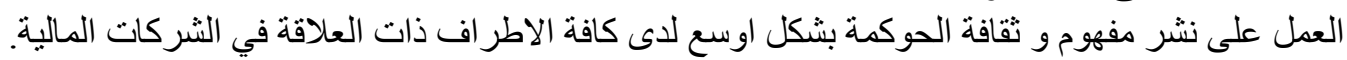

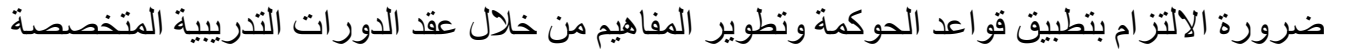
اللعالمين في هذه الثركات.

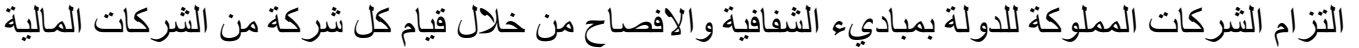

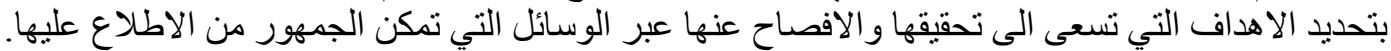

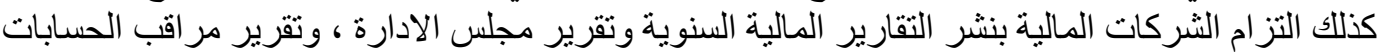

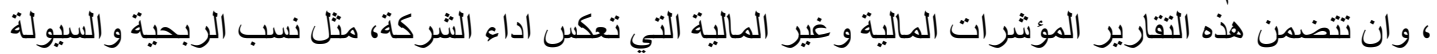

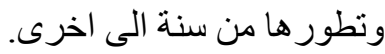
• تشكيل لجان التدقيق في الثركات من قبل الهيئة العامة وليس من قبل مجلس الادارة ويكون ارتباطها

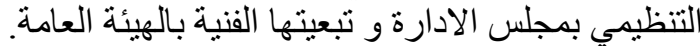

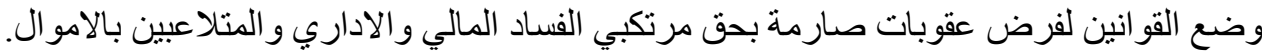

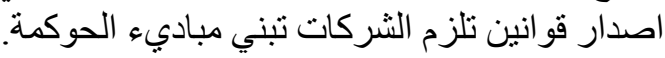

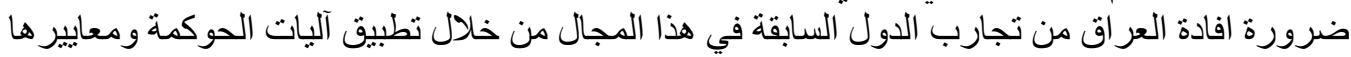

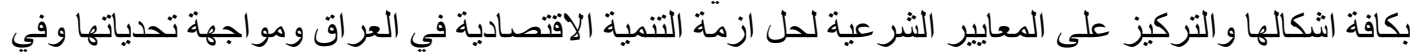

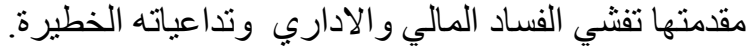
ضرورة تطبيق الحوكمة بأعتبار ها اداة ضرورية وفاعلة من ادوات الاصنا الصاح الاقتصادي. 


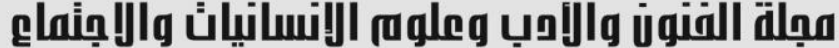

Journal of Arts, Literature, Humanities and Social Sciences
www.jalhss.com

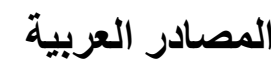

الكثب

1- سلام ، اسامة عزمي، وموسى، شقيري نوري ، 2010، ادارة الخطر و التأمين، الطبعة الاولى، دار الحامد

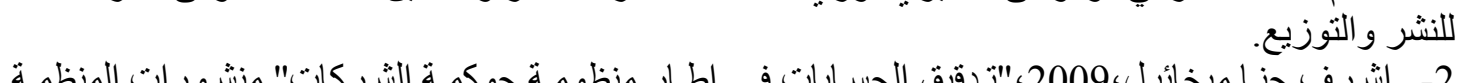

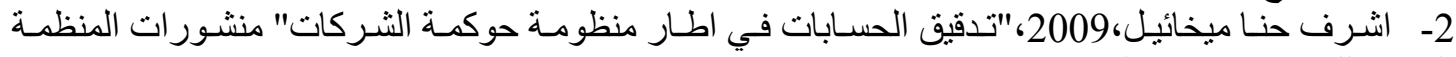
العربية للتنمية الادارية، القاهرة، صائن 92.

3- سليمان، محمد مصطفى،2006،حوكمة الثركات ولاتهة ومعالجة الفساد المالي و الاداري -

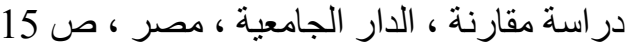

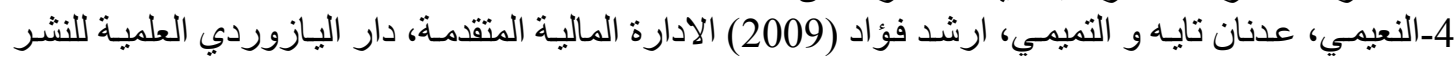

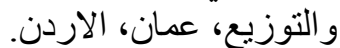

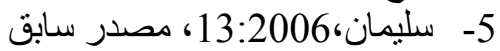

6- حمودة، محمود احمد ، 2006، 2011، دور آليات الحوكمة في مكافحة الفساد المالي،مدونها.

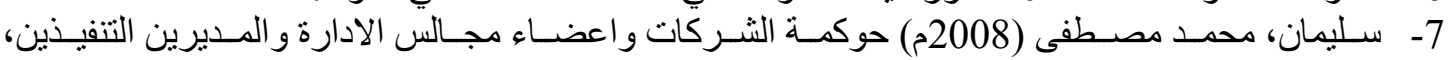

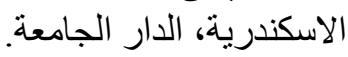

المجلات و المداخلات و النشر ات:

1- الحلبي ، نبيل (2009م) دور الحوكمة في زيادة ربحية المنشأت الصناعية في سورية ، مجلة جامعة دمشق

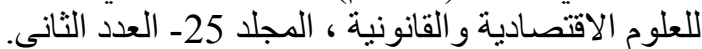

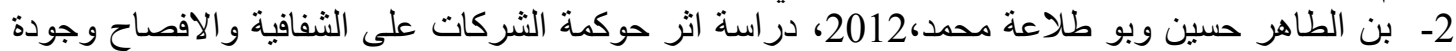

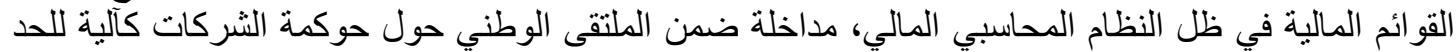

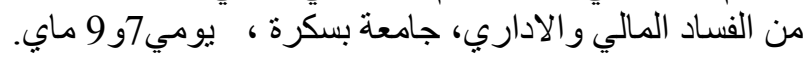

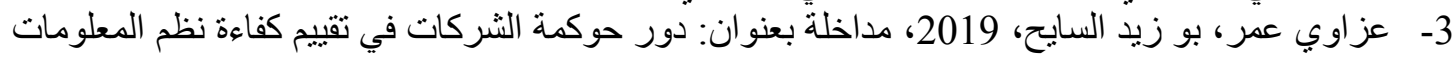

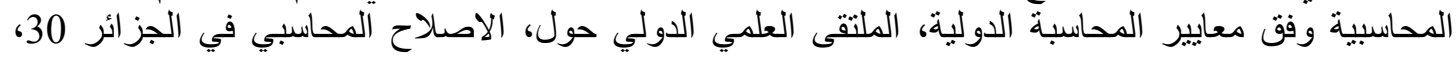

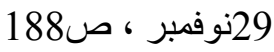
4- اساسيات الحوكمة، مصطلحات ومفاهيم، سلسلة النشر ات التثقيفية لمركز ابو ظبي للحوكمة، الامار ات

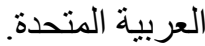
5- (منظمة التعاون الاقتصادي و التنمية ، 2004).

\section{References}

1-Salam, Osama Azmy, and Mousse, Shuqiri Nuri, 2010, Department of Risk and Insurance, First Edition, Al-Hamid House for Publication and Distribution.

2- Ashraf Hanna Mikhael, 2009, "Auditing Accounts within the Framework of Corporate Governance System," Arab Organization for Administrative Development Publications, Cairo, p.92.

3- Suleiman, Muhammad Mustafa, 2006, Corporate Governance and Addressing Financial and Administrative Corruption- A comparative study, University House, Egypt, p. 15

4-Al-Nuaimi, Adnan Tayeh and Al-Tamimi, Arshad Fuad (2009), Advanced Financial Management, Al-Yazurdi Scientific Publishing and Distribution House, Amman, Jordan.

5- Suleiman, 2006: 13, previous references.

6-Hammouda, Mahmoud Ahmad, 2011, The role of governance mechanisms in combating financial corruption, blog. 


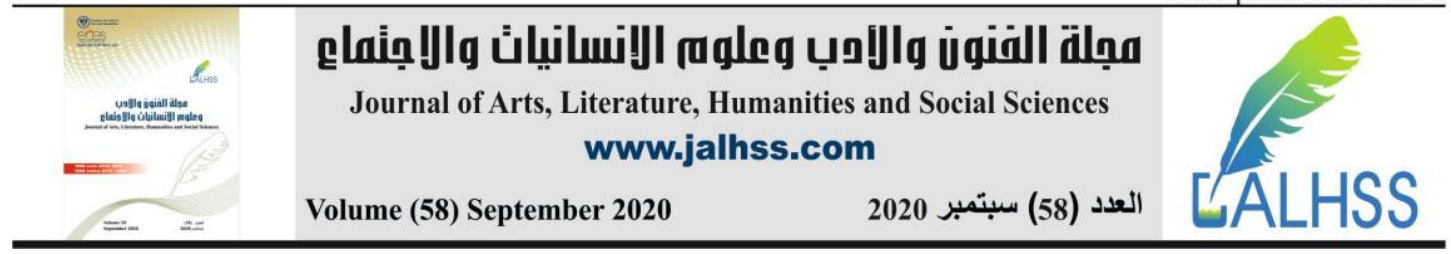

7-Suleiman , Muhammad Mustafa (2008 AD) Corporate Governance, Board Members and Executive Directors, Alexandria, University House.

\section{Magazines, entries and pamphlets}

1-Al-Halabi, Nabil (2009 AD) The Role of Governance in Increasing the Profitability of Industrial Establishments in Syria, Damascus University Journal of Economic and Legal Sciences, Volume 25 - Second Issue.

2-Bin Taher Hussein and Bou Tala'a Mohamed, 2012, Study of the Impact of Corporate Governance on Transparency, Disclosure and Quality of Financial Statements under the Financial Accounting System, Intervention within the National Forum on Corporate Governance as a Mechanism to Reduce Financial and Administrative Corruption, Biskra University, on May 7 and 9.

3-Azzawi Omar, Bouzid Al-Sayeh, 2019, an intervention entitled: The Role of Corporate Governance in Evaluating the Efficiency of Accounting Information Systems According to International Accounting Standards, International Scientific Forum on Accounting Reform in Algeria 30, 29 November, p. 188.

4-Corporate Governance Fundamentals, Terms and Concepts, a series of educational publications for Abu Dhabi Governance Center, United Arab Emirates.

) Organization for Economic Cooperation and Development, 2004(5-

\section{English References}

1. Beltratti, Audree (2005), The complementarity between corporate Govemance: and corporate social responsibility, the Geneva papers doi!

10.1057/palgrave.gpp.2510035.

2. Mohammed, soliman Ali Mohammed (2010), Role of Internal Control in Corporate Govemance: A case study of Ksc Ltd, Unpublished Master Thesis, college of Graduate studies and scientific Research, sudan University of science and Technology.

3. Torres, Damiana, Adriano LeaL Bruni, Antonio Lopo Martinez and MigueL Angel Rivera - Castro ,(2010),ownership and control structure Corporate Governance and Income smoothing in Brazil, Available at: http://ssrn.com/abstract=165/991 